\title{
Recommendations of the Polish Society of Physiotherapy, Polish Society of Family Medicine and College of Family Physicians in Poland in the scope of physiotherapy in painful shoulder syndrome in primary healthcare
}

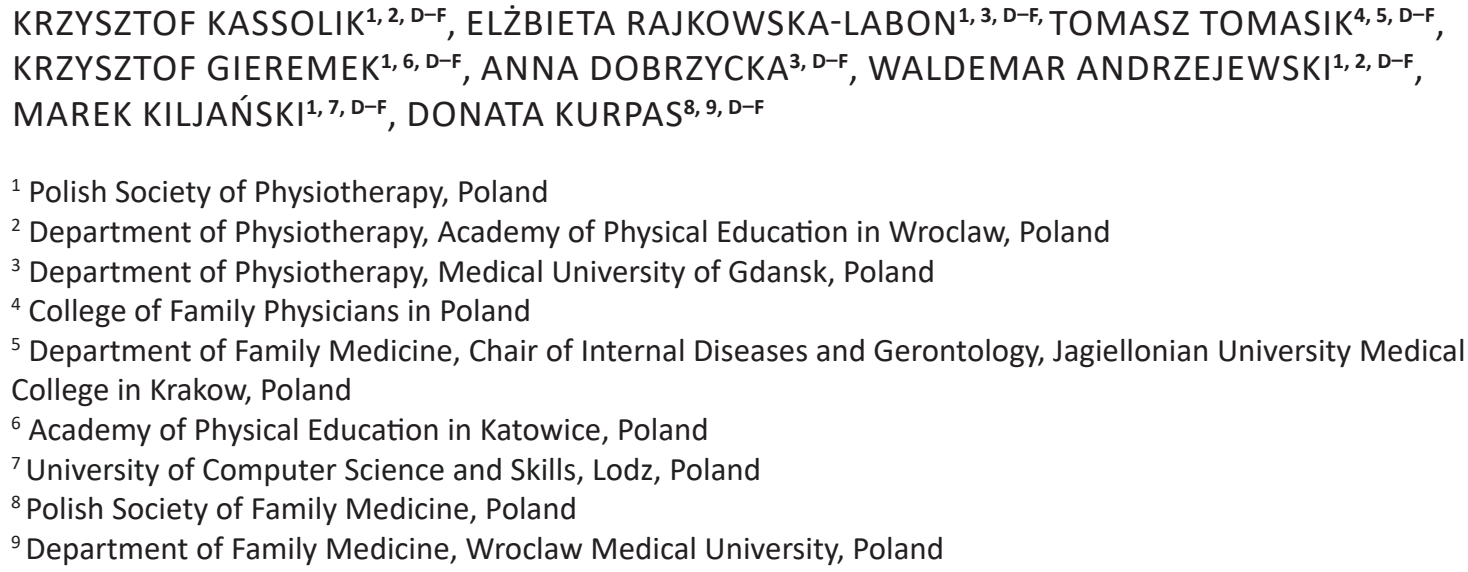

A - Study Design, B - Data Collection, C - Statistical Analysis, D - Data Interpretation, E - Manuscript Preparation, F - Literature Search, G - Funds Collection

Summary The objective of these guidelines in the scope of physiotherapy in primary healthcare is to suggest simple, uncomplicated and more cost-effective physiotherapeutic activities in patients experiencing pain due to painful shoulder syndrome. A general practitioner should decide whether the treatment undertaken within primary healthcare, including the process of physiotherapy, is effective and sufficient, or whether it requires more advanced activities, such as advanced diagnostics and further specialist treatment. The authors of the recommendations, apart from massage, also include procedures in the scope of kinesiotherapy, physiotherapy and orthopedic equipment. According to the authors, the aim of recovering the correct spatial system, called structural homeostasis, in the shoulder girdle, is, first of all, normalization of muscle tension and then inclusion in a rehabilitation program covering the methods to recover and consolidate the correct models of motor activity. The starting point for determining a rehabilitation program should be the ability to prepare a simple assessment of the patient's condition. This may result from a palpation examination to determine the incorrect distribution of resting tension in the area of the muscles and tendons engaged in the pathology and causing pain. The authors believe that such a solution contains the key to reducing the costs of treatment, providing access to physical therapists and quick assistance in the scope of improvement of a patient's clinical condition. At the same time, they emphasize the need to correct the previous healthcare model, so that it becomes a more effective tool in maintaining health.

Key words: general practitioners, shoulder pain, rotator cuff, shoulder injuries, shoulder impingement syndrome.

Kassolik K, Rajkowska-Labon E, Tomasik T, Gieremek K, Dobrzycka A, Andrzejewski W, Kiljański M, Kurpas D. Recommendations of the Polish Society of Physiotherapy, Polish Society of Family Medicine and College of Family Physicians in Poland in the scope of physiotherapy in painful shoulder syndrome in primary healthcare. Fam Med Prim Care Rev 2018; 20(3): 277-290, doi: https://doi.org/10.5114/ fmpcr.2018.78274.

\section{Background}

Pain associated with the musculoskeletal system is one of the most frequent causes of consultation in primary healthcare and usually affects more than one area of the body [1-3]. The third most frequent type of pain $[4,5]$, after back and hip pain, is painful shoulder syndrome, which constitutes a common problem in adults and has a negative effect on the ability to work, to perform everyday activities (driving, getting dressed, combing one's hair, preparing meals, eating), on sleeping and on the general quality of life [2, 6-9]. According to observations, the pains associated with painful shoulder syndrome are often chronic and recurring, and $40-50 \%$ of patients report persistent symptoms after 6 to 12 months, while $14 \%$ of patients continue treatment after 2 years [9].
Furthermore, it has been recorded that $10 \%$ of all referrals to physical therapists are associated with pain in the area of the shoulders [7]. With an ageing society and the relationship between more shoulder pain and age, according to estimates, more and more people with this diagnosis are going to report to their general practitioners [10].

As follows from a data analysis conducted in New Zealand, shoulder pain causes 14.7 persons per 1000 patients [11] to seek medical attention from family physicians, while in the Netherlands - 34 per 1000 [4].

Chester et al. indicate that the period of 2011-2012 was the first in Great Britain to record more cases of upper limb pain than cases of pain of the lumbosacral area [12].

In the Netherlands, clinical guidelines for general practitioners in the scope of treating patients with shoulder pain and recom- 
mendations issued by the Dutch Society for Physical Therapy for patients with suspected pain in the subacromial area are applicable. Physicians jointly determined a classification of patients with non-specific shoulder pain into three subgroups: the first subgroup is patients with pain during abduction (located in the subacromial space), the second one - patients with passive movement limitation (pain of the shoulder joint), and the third one - patients with pain during abduction and passive movement limitation (instability, pain of the acromioclavicular joint or neck) [4].

A tendency for chronic shoulder pain lasting over 6 months has been observed in working people [3]. Half of the patients reporting this problem to their general practitioners manage to recover in half a year, and just $60 \%$ - in a year [13]. The results of the lengthiness and poor effectiveness of treatment of painful shoulder syndrome are long periods of absence from work, and even cases of losing one's job, as well as rising costs of treatment $[1,14,15]$. The costs associated with treating and diagnosing shoulder pain in primary healthcare are not known in detail. According to estimates (based on Swiss and Swedish data), 47-87\% of the costs of treatment are associated with absence from work. It has also been observed that patients with direct access to physical therapists incurred lower costs related to healthcare [12]. In 2000, in the United States, the annual cost of treating patients with shoulder pain amounted to USD 7 billion [16]. The outcome of the therapy is affected by the period between the first incident of pain and the introduction of treatment, as painful shoulder syndrome is associated with pain in the area of the neck, and if lasting too long, it results in unsatisfactory results of primary care treatment [17]. Similar conclusions were included in a systematic review of 2013, which indicated that working patients aged 45-54 with chronic shoulder pain of significant intensity demonstrated worse results in the scope of physical therapy [12].

In the USA, ca. 4.5 million patients a year report to their physician, usually because of shoulder pain and incapacity resulting from rotator cuff impingement syndrome [16].

Shoulder pain, in particular the pain associated with rotator cuff impingement syndrome, is a common pain reported to a general practitioner. It follows from the research available that the general success ratio of conservative treatment is ca. $75 \%$ [18]. Research conducted on cadavers and radiological analyses demonstrated rotator cuff impingement syndrome in at least $10 \%$ of people aged 60 in the USA [19]. The estimated number of surgeries in this country resulting from rotator cuff impingement syndrome every year is between 75,000 and 250,000 patients. This number indicates that less than $5 \%$ of the patients in the USA with this type of damage were treated surgically [20].

On the basis of available literature, the authors noted that the key aspect of treating patients complaining about pain of the musculoskeletal system is cooperation between general practitioners and physical therapists $[8,9,21-23]$. The application of specialist diagnostic tests (MRI, ultrasound, arthrography, MRA) [24] should be proposed only at a later stage of treatment if physical therapy is not effective and if surgery is taken into account. [8]. As a result, it seems necessary to introduce systemic changes in diagnosing and treating patients with painful shoulder syndrome at the level of general practitioners. The recommendations include simple solutions, taking into account acting at the stage of first contact between patients and physicians. The authors present diagnostics of painful shoulder syndrome with diagrams supplemented with physiotherapy procedures, including massage, physical therapy, kinesiotherapy and orthopedic equipment, as well as emphasize the role of education and self-therapy.

\section{Objectives}

The objective of these guidelines in the scope of physiotherapy in primary healthcare is to suggest simple, uncomplicated and more cost-effective physiotherapeutic activities in patients experiencing pain due to painful shoulder syndrome.

\section{Methods}

Experts from the Polish Society of Physiotherapy, Polish Society of Family Medicine and College of Family Physicians in Poland conducted a detailed review of published scientific evidence associated with application of physiotherapy in painful shoulder syndrome in the years 1998-2018, published in the following databases: Pub Med, Cochrane Library. The search for articles was based on the following keywords: shoulder pain, pain, rotator cuff impingement syndrome, epidemiology, etiology, risk factors, guidelines. Of the articles found, the authors selected those that are comparable with the Polish primary healthcare system. A model of physical therapy procedure in patients with pain in the area of the shoulder was presented.

\section{Definitions}

As diagnostics of painful shoulder syndrome are complex, literature lists several conditions associated with pain in the shoulder joint, and the classification is mainly based on Codman's publication "The Shoulder". The following were differentiated:

- rotator cuff impingement syndrome,

- tendinopathy musculus biceps brachii,

- disorders in the area of the acromioclavicular joint,

- adhesive capsulitis (frozen shoulder),

- injuries of the shoulder joint (dislocations, fractures),

- non-specific shoulder pain $[23,25,26]$.

Below can be found definitions useful in diagnosing pathologies connected with painful shoulder syndrome:

a) rotator cuff impingement syndrome (RCIS). Lädermann et al. considers rotator cuff impingement syndrome to be a condition in which at least two tendons are completely torn. Apart from torn tendons, at least one of the two tendons must be located behind the apex of the head of the humerus bone [27]. The clinical advancement in this diagnosis is determined by the number of injuries of the shoulder joint rotator tendons. Collin et al. classified impingements of the apex into 5 categories, $A-E$, depending on the location and number of damaged tendons. In turn, Cofield based his clinical classification on the size of damage. He listed: small (up to $1 \mathrm{~cm})$, medium $(1-3 \mathrm{~cm})$, large (3-5 $\mathrm{cm}$ ) and massive (over $5 \mathrm{~cm}$ ) impingements of the tendon [27].

b) tendinopathy musculus biceps brachii. The most typical symptom is pain in the intertubercular groove of the arm, intensifying during compression [28]. Singajaru et al. claim that the main cause of pain in the anterior part of the shoulder is pathology of the LHBT (long head of the biceps tendon) [29].

c) subacromial impingement syndrome (SIS), commonly referred to as subacromial conflict. Pains are defined as pain in the shoulder joint radiating to the area between the neck and the elbow. A gradual deterioration of the motion range and intensification of pain during movements of the upper limb over the head is observed [25].

d) frozen shoulder syndrome (FSS). The current definition used by American surgeons, specialists in pathology of the shoulder and elbow joints, associated with adhesive capsulitis is as follows: "a condition of uncertain etiology, characterized by significant limitation of the active and passive movements of the shoulder, appearing in the absence of a known unequivocal internal dysfunction of the shoulder-blade" [30]. Le et al. define frozen shoulder syndrome as a pathological process caused by inflammation of the joint capsule and its arthrofibrosis caused by excessive scar tissue or adhesion in the area of the whole shoulder joint, leading to rigidity, pain and dysfunction [31].

\section{Epidemiology}

Painful shoulder syndrome appears in $18-31 \%$ of the total population [7]. According to estimates, in Great Britain, this 
affects $14 \%$ of the British population [23]. In Europe, shoulder pain appears in $19 \%$ of the total population [32]. Of all the reported complaints of this area, SIS is the most frequent disorder and appears in $89 \%$ of all the reports submitted to general practitioners and physical therapists [33].

Complaints of the arm, neck or shoulder constitute a large proportion of work-related musculoskeletal disorders. It follows from research conducted on the Dutch population that after 12 months, $58 \%(n=404)$ of persons suffering from chronic pains used the assistance of a general practitioner, specialist or physical therapist [34]. Medical advice associated with chronic CANS was provided to females more often than males $(7.0 \%$ and $4.1 \%$, respectively). What is more, the rate of using medical assistance by persons with chronic CANS is higher in the working population than among the unemployed [34]. It should be emphasized that CANS results from multiple factors. Predispositions include: psychosocial properties, personal and environmental factors. The significance of every element in causing pain is different and depends on the character of work $[25,34]$.

A review of literature indicates a significant correlation between pain of the musculoskeletal system and the type of work (work-related musculoskeletal disorders) [35, 36]. The high-risk group includes persons working with computers and manual workers. According to studies conducted on 513 office workers, $50.5 \%$ of them reported shoulder pain [37]. In this group of patients, the pain correlates to age and work experience [38]. It should be noted that, in most cases, their pain was non-specific [26]. Painful shoulder syndrome also often appears in healthcare professionals. The most exposed groups are nurses, physical therapists and dentists, of whom $23.5 \%$ report shouldered pain [39]. According to other reports, the above problem appears in $40 \%$ of nurses, midwives and physical therapists [40] and $18 \%$ of dentists [41]. It follows from the latest research that $52.39 \%$ of nurses above the age of 26 experience shoulder pain, mainly resulting from working over 40 hours a week [42]. Of those operating ultrasound equipment, $66.1 \%$ reported the above-mentioned issue on the left side of their body [43]. It follows from research into location of the pain in the musculoskeletal system and analyzing its occurrence in terms of frequency and prevalence that the percentage of patients with painful shoulder syndrome changed between $38 \%$ and $58 \%$ in the examined population, depending on the source [44]. Under the 2018 meta-analysis, the issue related to rotator cuff impingement appeared in $18 \%(300$ of 1,513$)$ of surgeons. The researchers emphasized the lack of awareness of the risks and the need for promoting knowledge of work ergonomics [45].

$3-5 \%$ of the population is diagnosed with "frozen shoulder syndrome", usually people with diabetes and hyperthyroidism aged 40-59 [31, 46]. The pains may appear suddenly and progress gradually.

Shoulder pain may also be associated with certain sports disciplines. Of 340 athletes, this was experienced by $43.5 \%$ of people, of whom the highest ratio was people training at handball and judo [47]. It follows from other research that $40 \%$ of female volleyball players experienced non-traumatic shoulder pain, but only $33 \%$ of them took a break from training to treat it [48]. Other athletes exposed to shoulder joint injuries are tennis players [49] and disabled athletes in wheelchairs (16-76\%) [50].

\section{Etiopathogenesis}

Due to the complexity of the causes of shoulder pain, the process of diagnosing them sometimes requires detailed diagnostics. Pain in this area may appear in the course of: diseases of blood vessels, nerve diseases and injuries, internal diseases, developmental disorders [28].

Painful shoulder syndrome constitutes a complex diagnostic issue for general practitioners. When determining treatment, structural lesions are noticed only in some cases, and if they are not - they result in further progression of the dysfunction (rotator cuff impingement) [51]. Chronic, non-specific shoulder pain is a more and more frequent problem requiring medical advice [52]. The causes include psychosocial factors, such as stress at work, relationships with colleagues, somatization, anxiety, depression or depressive disorders [3, 26, 53]. Attention is paid to the relationship between the incidence of painful shoulder syndrome with an uncomfortable body position, a high degree of motor monotypy associated with the upper limb and excessive physical exertion of the upper limbs combined with lifting heavy items or lifting items above the head $[51,54,55]$. Other causes include: age, female gender, obesity, marital status, smoking, hypercholesterolemia, fibromyalgia, rheumatoid arthritis, multiple sclerosis, genetic factors and vibrations resulting from work-related requirements $[10,14,26,56]$.

Shoulder pain should be examined not only in terms of the shoulder joint itself, but of the whole shoulder girdle. The pathology may refer to anatomic joint connections (acromioscapular joint, sternoclavicular joint, acromioclavicular joint), functional connections (scapulothoracic joint, subacromial joint), as well as muscles, tendons, nerves and vessels. Due to the degree of complexity of the above-mentioned structures that are interdependent in biomechanical, anatomic and functional terms, diagnostics and differentiation between pains may sometimes prove unsuccessful or prolonged $[2,57]$.

Due to the extent of the pathomechanisms causing dysfunctions in the area of the shoulder girdle and the associated limitations, the authors of these recommendations emphasize certain pains of the shoulder caused by orthopedic pathologies and agree that, apart from physical therapy, in justified cases, more technologically advanced diagnostics and specialist treatment should also be used, e.g. in the scope of neurology, internal diseases, neurosurgery, vascular surgery, orthopedics. However, they emphasize that, regardless of the more or less complex causes or pathomechanisms of the shoulder, the clinical joint symptoms appearing even at the initial stage of development of painful shoulder syndrome, include pain, disrupted the distribution of resting tension in the soft tissues, limited functionality. A general practitioner should decide whether the treatment undertaken within primary healthcare, including the process of physiotherapy, is effective and sufficient, or whether it requires more advanced activities, such as advanced diagnostics and further specialist treatment. The authors believe that such a solution contains the key to reducing the costs of treatment, providing access to physical therapists and quick assistance in the scope of improvement of a patient's clinical condition. Below we refer to the most frequent clinical diagnoses leading to shoulder pain.

Rotator cuff impingement syndrome (RCIS) refers to the following muscles: supraspinous, subspinous, subscapular and teres minor muscles. Structural lesions are usually observed in people in their 50s and are associated with ageing. The pathology usually appears in the tendon of the supraspinous muscle. Imbalance in muscle tension in the area of the rotator cuff not only results in inflammation of their attachments, but also in instability of the shoulder joint. Rotator tendons may be damaged as a result of: degenerative lesions, recurring microinjuries or significant injuries (falling on a stretched arm, pushing or pulling of the limb with significant power, displacement of the shoulder resulting from excessive movements), atraumatic irritations (e.g. repetitive movements) and secondary dysfunctions [58].

Effects may include inflammation of the musculus biceps brachii. The cause of inflammation in that area may also be a past injury or excessive strain $[26,59,60]$. Physicians recommend an MRI to diagnose the causes of rotator cuff disorders. It follows from observations that $40 \%$ of persons without symptoms after the age of 50 demonstrate irregularities in such an image [58].

Tendinopathy musculus biceps brachii. This diagnosis rarely occurs as an individual clinical problem. The pain is often re- 
lated to dysfunction of the supraspinous muscle $[60,61]$. The joint occurrence of lesions is especially justified, as the research conducted by Braun et al. confirms the anatomic and functional relationships between the listed structures [62]. Tendons of the above-mentioned muscles are engaged in stabilization of the head of the humeral bone, and damage to one tendon may affect the functionality of the other [60]. The most frequent causes of LHBT tendinopathy include inflammatory, traumatic and degenerative factors [60]

Subacromial impingement syndrome. A lot of factors are associated with potential development of SIS, including: anatomic irregularities in the coracohumeral arch or the head of the humeral bone, ischemia associated with tension overload, recurrent eccentric overloads, incorrect kinematic patterns caused by debilitation of rotator cuff muscles and dysfunction of the scapula stabilizer muscles and body posture disorders [63]. It has been demonstrated that four independent risk factors are related to SIS [64]. The first one is cigarette smoking (7 times higher risk of development of SIS in comparison with non-smokers). Cause: debilitated vascularization and extended healing time caused by consumption of nicotine. The second one is sleeping position (sleeping on the side was demonstrated as causing a 3.7 times higher risk of development of SIS than sleeping in the supine position). The third one is the shape of the acromion (the risk of development of SIS increases 6.3 times in the case of the hook shape in comparison with the flatter shape). The fourth one is profession, sports and daily activities which may increase the risk of development of SIS (in particular movements of the limb that are repetitive, uncomfortable, overburdening or leading to improper posture) [65]. The dysfunction usually causes pain of the anterio-lateral part of the shoulder joint. Other authors believe the cause of pain is pathological overloading and microinjuries of the supraspinous muscle. Another etiology is balance disruption during activity of the deltoid muscle and rotator cuff muscles, leading to destabilization of the connection between the head of the humeral bone and the joint socket. In the advanced stage of the disease, the rotator cuff is partly or completely damaged, and joint arthritis appears. [66]. In 50\% of patients with acute symptoms of SIS, after medical intervention by a general practitioner, the pain sometimes disappears after 6 months, and in $40 \%$ - after 1 year. These results suggest that the condition in $10 \%$ of patients suffering from acute pain will not improve satisfactorily. Furthermore, $50 \%$ of patients with SIS and chronic pain may expect a relapse after 10,12 or 18 months of the occurrence of the first symptoms [14].

Frozen shoulder syndrome. The etiology is usually idiopathic, and symptoms appear without a recognized cause [31]. The symptoms that accompany pain include: debilitation, rigidity, crepitation, edema, fear of movement, sometimes imbalance [2]. The predisposing diseases include hyperthyroidism, diabetes, hyperlipidemia and cerebrovascular diseases. Trigger factors include: immobilization, emotional experiences, mental strain $[31,66]$. The incidence frequency is also higher in patients with Dupuytren's disease and Peyronie's disease and in patients after surgery of the heart or of the cervical spine [67]. It usually appears in females aged 40-60 and affects the dominant hand [66]. Other researchers record higher predilection in white patients, patients with a positive family history and with a positive HLA-B27 antigen [68]. The course of the disease may be acute (< 6 weeks), subacute (6-12 weeks) or chronic ( 6 months). There are 3 stages of the disease: freezing, frozen and thawing $[2,67]$. Some researchers indicate four phases in the course of adhesive capsulitis. The first phase may last between 3 and 6 months and is characterized by acute pain, usually while resting. In the next phase, the pain subsides, but the result of the first phase is stiffness and further limitation of movement in all directions. The third phase is characterized by limitation of pas- sive and active movements in every plane. In the last part of the course of the disease, there is observed a smaller level of pain and stiffness and gradual recovery of lost functionality, but as many as $50 \%$ of the patients never regain full mobility as was before the disease [26]

In their publication, Georgiannos et al. refer to formal diagnostic criteria, which include: 1 . pain and progressive stiffness of the shoulder joint for at least 4 weeks; 2 . strong shoulder pain making daily activities or work difficult; 3 . night pain; 4. painful limitation of the range of shoulder movements, both during passive and active operation (height $<100^{\circ}$, limitation of external rotation by $50 \%) ; 5$. untypical radiological image [69].

\section{Clinical picture}

Shoulder pain may significantly affect the functioning of the whole upper limb. The initial pain comes from the tissues supporting the structure of the shoulder joint [2]. They usually appear in the superior-lateral part of the shoulder, which may radiate to the neck and elbow. It appears in the shoulder joint during passive and active movements and may appear at night [14].

\section{a) Interview}

During the interview with the patient, attention is paid to such information as: course of the disease, history of injuries, dominant side, pain location, direction of movement that provokes pain, character of pain, type of work, effect of pain on sleep, co-existing diseases [23].

\section{b) Functional assessment and clinical tests}

The most frequent tool for assessing pain is the visual analog scale (VAS) concerning general feeling, during active movement and while sleeping. The active range of movement is then measured (flexure, extension, abduction, adduction, internal and external rotation) using a goniometer or tape measure [52]. Functional assessment usually consists of a Constant-Murley Score (CMS) questionnaire and a Shoulder Pain and Disability Index (SPADI) [70, 71]. Another useful test for identification of rotator cuff damage is a scapula stability test and a test of passive abduction in the patient's shoulder joint. Pain during movement means the result of the test is positive [72]. Damage to the tendon of the biceps brachii muscle is demonstrated in difficulty with flexure while lifting items to the height of the chest and pain in the anterior part of the shoulder [73]. Adhesive capsulitis is characterized by pain during passive external rotation movement of the shoulder [31, 74]. Detailed diagnostics associated with choosing a specific test for examining shoulder joint dysfunctions and the methods of performing them exceed the main purpose of this study.

\section{c) Palpitation examination}

During palpation examination of patients with shoulder pain, it is important to understand the anatomical connections and relationships in the discussed area. The basic anatomic structures include: proximal part of the humerus, the clavicle, scapula and ribs, the cortical and thoracic areas of the spine, as well as the muscles, tendons and ligaments surrounding and stabilizing these structures [2]. Assuming that the basic therapeutic objective of a general practitioner is reduction of pain in the shoulder, recovering the range of movements and improving functionality, it is necessary to conduct a palpation examination in order to obtain information on which muscles demonstrate intensified tension and tenderness and which limit movements. This may be conducted by checking the pressure sensitivity in the areas of their attachment, as presented in Table 1 [75-77]. 


\begin{tabular}{|c|c|c|c|c|c|c|c|c|c|c|}
\hline & 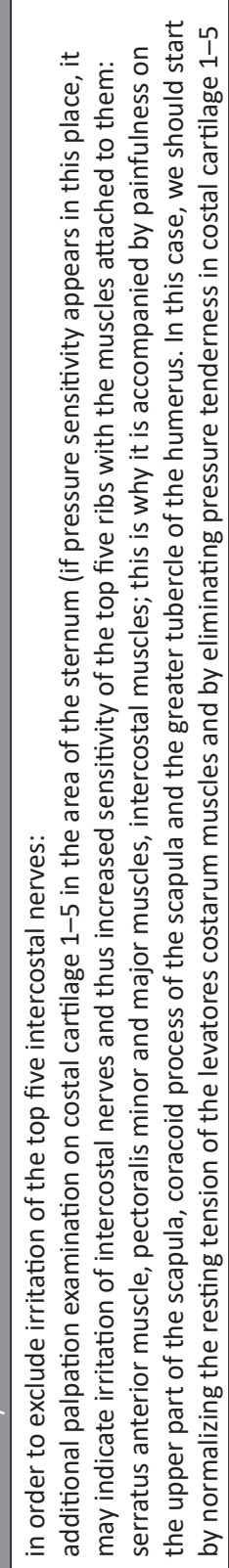 & 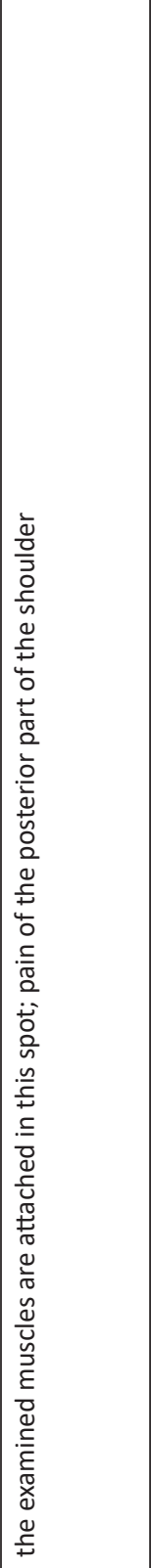 & 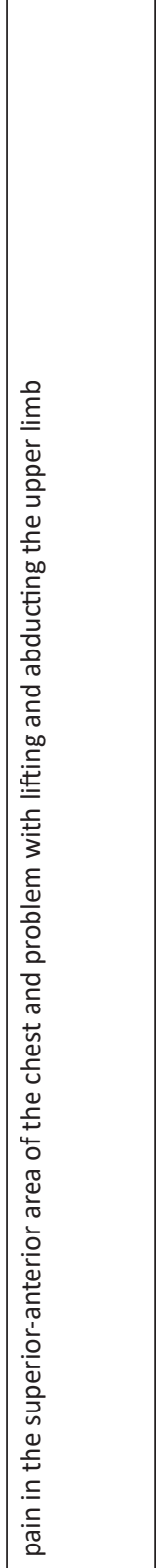 & 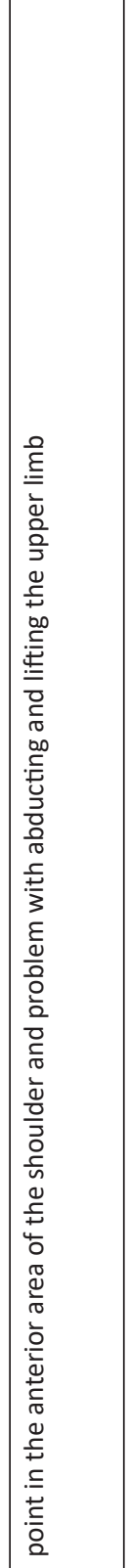 & 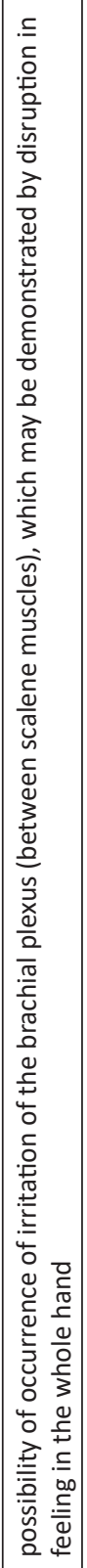 & 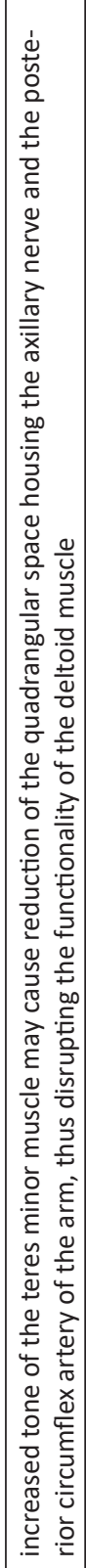 & 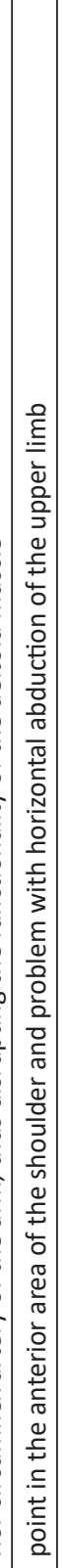 & 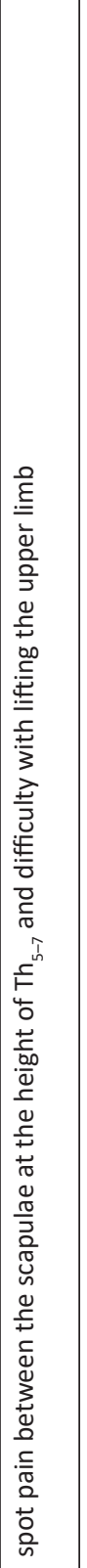 & 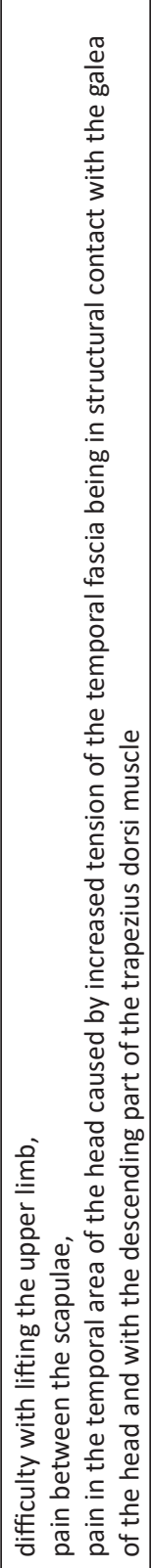 & 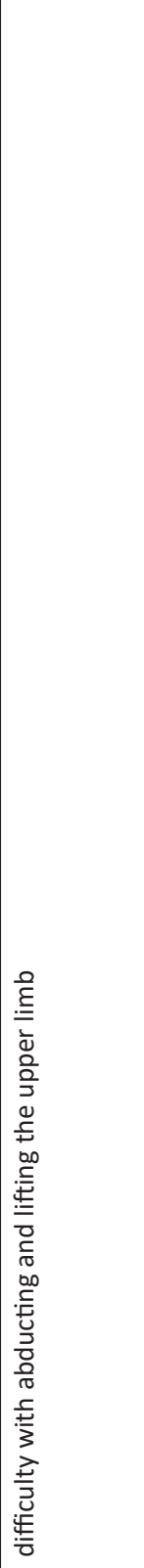 \\
\hline 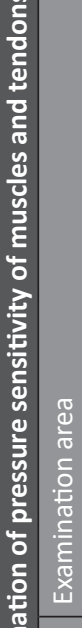 & 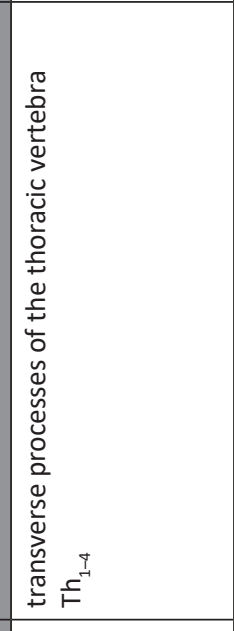 & 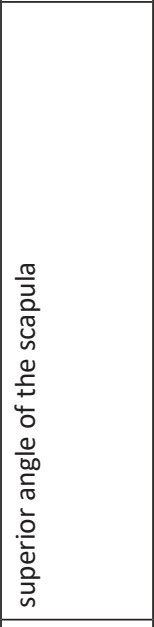 & 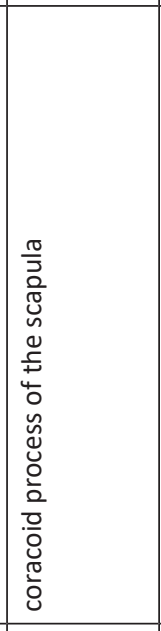 & 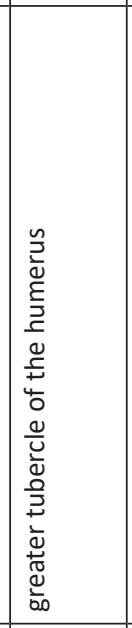 & 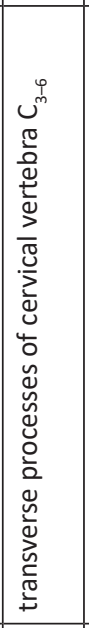 & 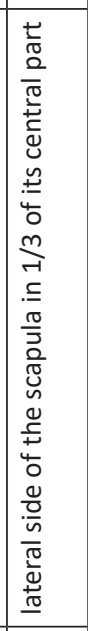 & 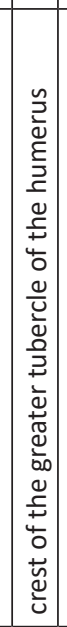 & 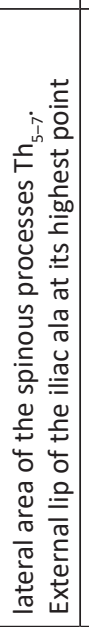 & 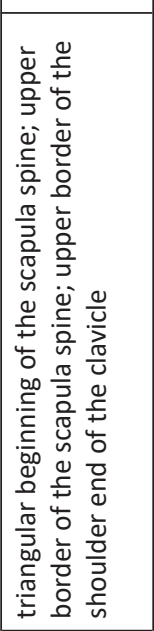 & 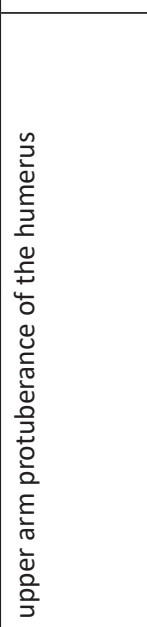 \\
\hline 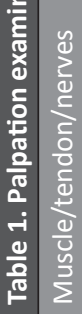 & 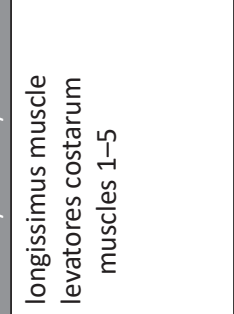 & 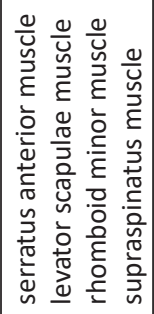 & 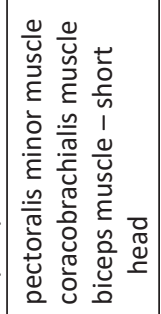 & 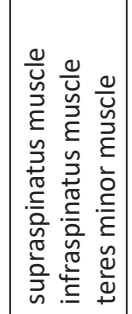 & 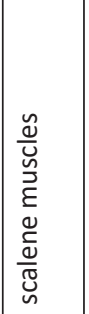 & 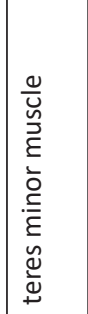 & 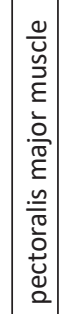 & 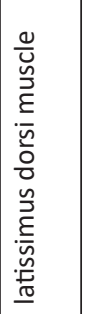 & 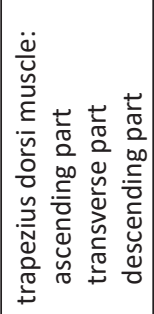 & 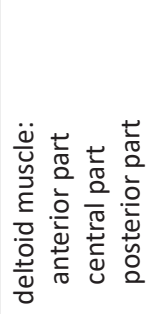 \\
\hline
\end{tabular}




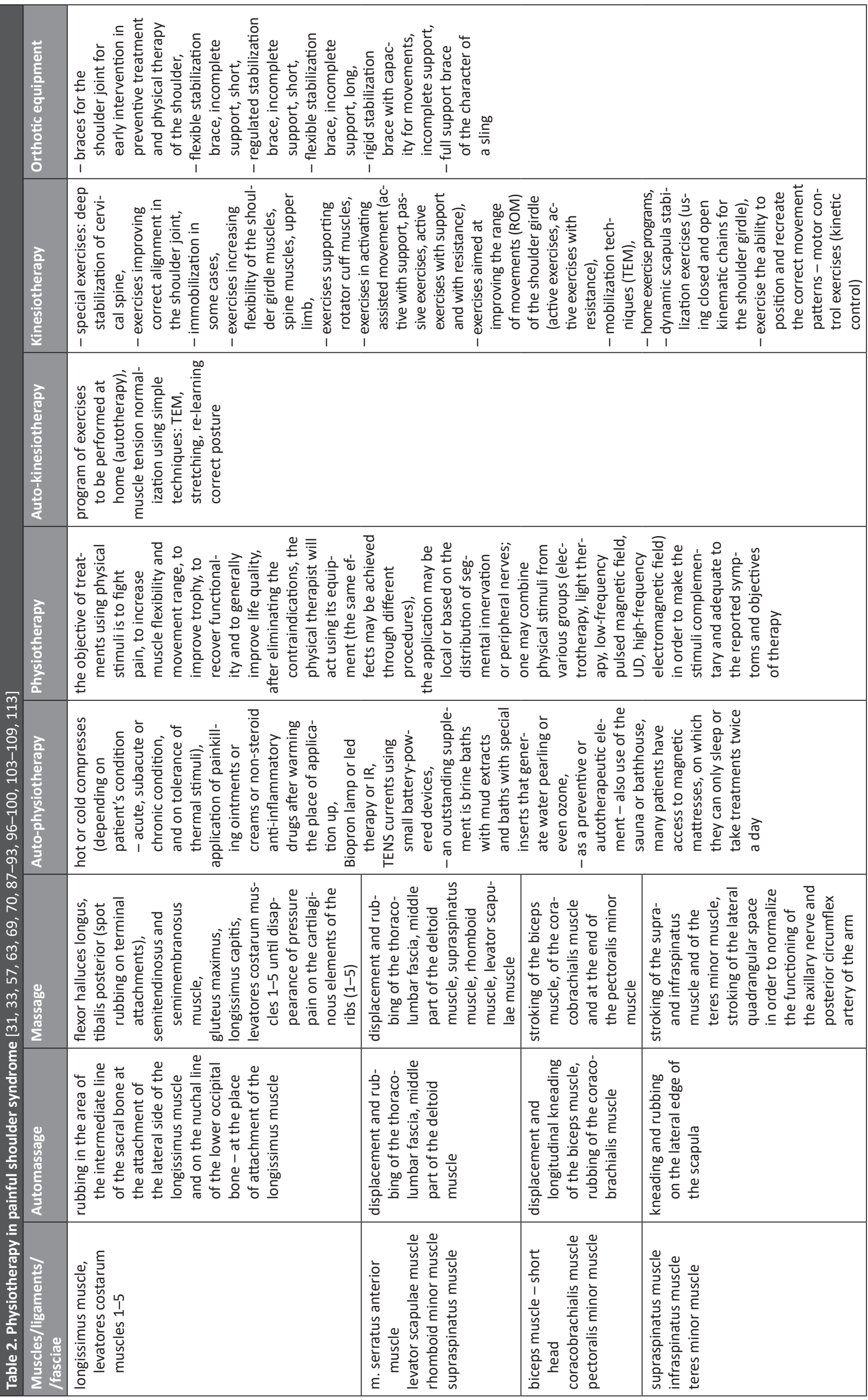




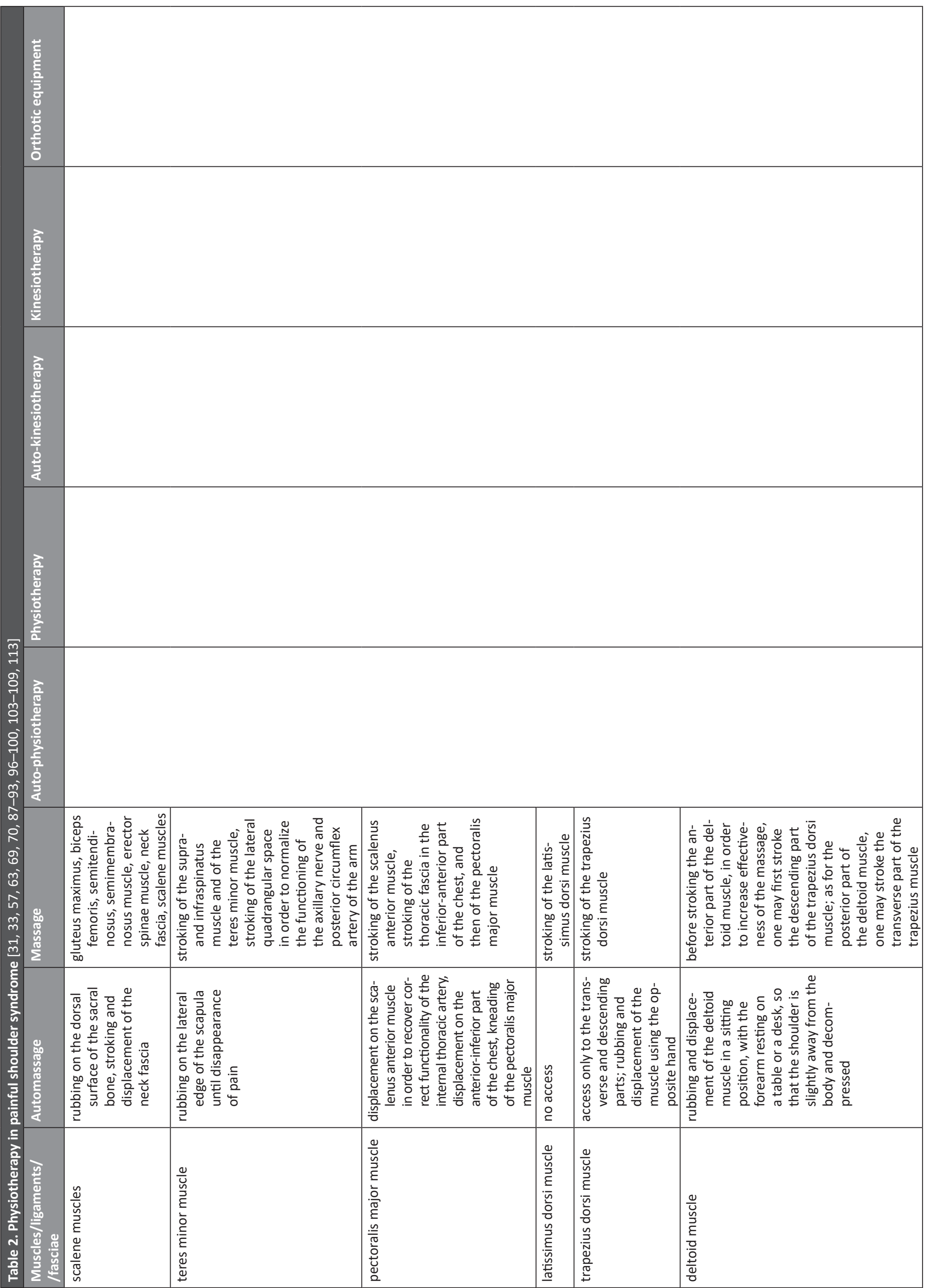




\section{Physical therapy strategy}

The main objective of physical therapy within primary healthcare is to use it in patients that most frequently use that form of treatment and to deal with so-called low-risk patients. This approach is proactive and aims to increase patients' responsibility for the process of therapy for current pains and prevention of relapse. The main emphasis is placed on preventive physical therapy, i.e. forms of broadly-understood education, access to finished studies and understandable selection of physical therapy activities that may be performed by the patient on his/her own at home, as well as preparation of descriptions of exercises and automassage, drawings, recordings, advice. Another important element should be education in ergonomic principles in everyday life and in protection against excessive overloading during regular everyday activities, thus eliminating the factors that maintain the risk of relapse of pain and developing useful motor strategies. Therapy should concentrate on the following tasks:

1) normalization of resting tension of muscles and fasciae (massage and poisometric muscle relaxation);

2) recovery of correct trophy in the tissues and organs of the motor system (inflow of arterial blood and effective discharge of venous blood and lymph), which provides conditions for correct regeneration or repair processes (in the case of tissue damage - past trauma or inflammation);

3) withholding of atrophy processes in muscles and connective tissue elements (ligaments, tendons, fasciae) - recovery of their structure and thus capacity (massage, physiotherapy, kinesiotherapy);

4) re-learning of correct movement patterns through targeted motor exercises of various degrees of complexity (kinesiotherapy), individualization of the rehabilitation program;

5) application of proper orthotic equipment and technical aides, as needed.

\section{a) Massage}

Available literature usually lacks details on the power of the respective stimuli used during various massage techniques, on frequency parameters, duration and depth of penetration and location of the massaged structures. The above reservations constitute a serious obstacle to comparing the results of own studies with the publications of other researchers [81]. A review of twelve studies of high methodological quality demonstrates the short-term effectiveness of massage in reducing pain of the shoulder, lack of significant functional improvement of the upper limbs or of a long-term painkilling effect [85]. As painful shoulder syndrome affects multiple structures, and previous studies were based on local work, the recommendations are going to include massage based on the principles of tension shifting in the areas of groups of muscles and fasciae in structural contact with each other, taking into account vessel and nerve connections [86]. Therefore, the structures in distant body parts, with structural relationships with the muscles and fasciae of the area of the shoulder, are also going to be massaged. As a result, it will be possible to recover correct innervation of the shoulder area, mainly from intercostal nerves, the brachial plexus and axillary nerve, as well as normalization of blood circulation from the anterior and posterior circumflex humeral artery and from the internal thoracic artery.

\section{b) Physiotherapy}

The selection of physical stimuli in skeletomuscular dysfunctions is based on symptoms. In painful shoulder syndrome, the main objective of physical treatments is to fight pain, to increase muscle flexibility and movement range, to recover functionality and to generally improve quality of life [70].

Based on a literature review by Page et al., it is known that using low-level laser therapy (LLLT), high-intensity laser therapy
(HILT), therapeutic ultrasound, transcutaneous electrical nerve stimulation (TENS) and pulsed electromagnetic field therapy (PEMF) require further placebo-based research in order to confirm their clinical effectiveness [70].

In turn, the team of White et al. claim that other non-conventional methods of pain treatment are losing out in light of opiate epidemics and concentration by the medical community on pharmacotherapy. They indicate clinical trials describing the advantages of using electrotherapy and laser therapy as adjuvant treatment in treatment of both acute and chronic pain. According to the FDA, "non-pharmacological attitudes to pain treatment have been considered an urgent priority" [87]. It follows from the prepared literature review that TENS demonstrates poor evidence for effectiveness of pain relief in patients with fibromyalgia and is much less effective than electroanalgesia in the form of electro-acupuncture (EA) or percutaneous electrical nerve stimulation (PENS) [87]. As regards laser light therapy, what has been indicated has been a higher effectiveness in elimination of pain through the use of HILT in comparison with LLLT in the treatment of rotator cuff pain (pain and disability minimization, improvement of movement range) [87, 88 ] and in muscle and fascia pain of the trapezius dorsi muscle [89]. A short-term painkilling effect using HILT was confirmed in patients treated for subacromial conflict, frozen shoulder or inflammation of the lateral epicondyle of the humerus. However, the authors emphasize that it is necessary to conduct research on a greater scale in order to verify the advantages of HILT in comparison to LLLT and electrotherapy in reducing acute and chronic pain, as well as observations of the long-term effects of therapy [87]. It follows from the observations by other authors, however, that LLLT is more effective than a placebo or ultrasound in subacromial conflict syndrome, just like shockwave therapy is more effective than placebo therapy in the case of persistent shoulder tendonitis [90].

It follows from a literature review prepared by the team of Page et al. that $80 \%(16 / 20)$ of participants reported success in treatment of frozen shoulder using LLLT in comparison with $10 \%(2 / 20)$ of participants from the placebo group. Similar observations were made for pulsed electromagnetic field therapy (PEMF). Due to poor quality, evidence for the effectiveness of this therapy is uncertain. However, after a two-week cycle of treatments, a more effective improvement was observed, in terms of pain and functionality, than in the placebo subgroup. $75 \%(15 / 20)$ of participants reported a decrease in pain by $30 \%$ in comparison to $0 \%(0 / 12)$ from the placebo group [91].

The authors studying the impact of physical procedures (low-level laser therapy and ultrasound) on reducing myofascial pain syndrome (MPS) observed that laser therapy is the preferred type of therapy in reducing the myofascial pain of that area [92].

In another article, the authors reported the effectiveness of application of UD in the treatment of calcerous shoulder tendonitis, but they emphasized that there is little evidence for the significant clinical effectiveness of this method [93]. The positive effects of treatment of calcerous shoulder tendonitis using shockwaves were discussed in an article by the Yu team. At the same time, the authors emphasized that a review of literature demonstrated a lack of unequivocal evidence for the effectiveness of shockwave treatment in SIS [90].

In a randomized clinical trial, the team of Gomes et al. studied the impact of interference currents on pain related to SIS. It follows from analyzing the obtained data that adding interference currents to the subgroup with exercises and manual therapy, despite reducing pain, did not significantly improve the result in the NRS (Numeric Pain Rating Scale) [94].

It follows from another study (evidence level $1 \mathrm{~b}$ ) conducted by Rabini et al. that in patients with rotator cuff tendinopathy, the impact of local microwave diathermy on disability, arm functionality and pain was equivalent to the effects caused by subacromial injections of corticosteroids [95]. 


\section{c) Kinesiotherapy}

Shoulder pain is a frequent problem, in particular among adults. What is most important in making the decision on which therapy to choose is a diagnostic conclusion based on a systematic (subjective, objective taking into account functional tests) study that allows one to find and specify the actual causes of pain [96].

However, regardless of the etiology of pain, therapy based on pain control and rehabilitation using therapeutic exercises are applied in almost all of the above-mentioned clinical trials, as well as physical procedures and elements of manual therapy. The complexity of causes of shoulder dysfunctions results in continuous discussions as to the manner of pain control and functional recovery of movement range [97]. The obvious aim of the proposed therapies is fast recovery achieved through regained mobility (proper flexibility of soft tissues), muscle strength, pain elimination and recovery of lost or limited functionality in the shoulder joint. In the case of lack of unequivocal causes of pain, some shoulder-related problems may result from incorrect posture and disrupted distribution of muscle tension in the upper and lower parts of the back and neck, and this should be taken into consideration in therapy planning [98].

Work-related skeletomuscular disorders of the upper limbs and neck are some of the most frequent work-related disorders in the world. It follows from the randomized research conducted by Zebis et al. that high-intensity strength training, based on the principles of progressive loads, may be implemented among employees (working in static positions with a curved neck) and result in a clinically significant reduction in neck and shoulder pain in this group. Employee training included dynamic high-intensity muscle work with gradual load progression [99].

Other authors, before planning therapy procedures, analyzed in detail both the range and course of movements. Analysis of the scapulohumeral rhythm allowed one to assess shoulder joint alignment and quality of scapula movement (direction and range) and to follow the irregularities resulting from disruption of motor control of the muscles (in particular the trapezius dorsi muscle and the serratus anterior muscle) [101].

\section{Rotator cuff conflict}

The treatment plan in rotator cuff impingement in primary healthcare depends on several critical variables. The following factors should be taken into account in therapy planning: age, profession, pain level, initial functional capability and co-existing diseases. Proper pain control is important for motivating patients to participate in rehabilitation [18].

According to numerous authors, the exercises improving movement of the shoulder joint and girdle (in the scope of flexion, abduction, external and internal rotation) and recovering shoulder girdle flexibility and muscle strength include: posture exercises, pendulum exercises using the upper limbs, slow active exercises (e.g. raising shoulders), active exercises with support (suspension), active exercises with support and resistance, exercises with a prop (e.g. a cane) to support active movement, exercises with flexible resistance (TheraBand) or dumb-bells. During therapeutic sessions, isotonic exercises, as well as static loads and isometric muscle work, were used. Furthermore, an important element of the kinesiotherapeutic program of rehabilitation is exercises stabilizing the scapula, performed in a lying position with and without load, with control of the scapula activity model [33, 97, 101, 103].

Kuhn suggests, in order to maintain shoulder fitness, reinforcing the therapy effects by applying, in home therapy, daily exercises improving muscle flexibility and range of movement in the joint and to use muscle strengthening exercises 3 times a week [97]. In order to improve flexibility of pectoral muscles and external rotators of the shoulder joint, it is recommended that autotherapy include stretching $[103,104]$.
In earlier publications, the authors emphasized that so far there is no convincing evidence for the effectiveness of physiotherapy in long-term improvement or in preventing a relapse of shoulder pain. It also follows from randomized controlled trials that there are no premises for applying physical procedures and various combinations thereof. Although motor therapy is considered to be the "cornerstone" of physical therapy, there has only appeared limited evidence for its effectiveness, which requires further research [105].

\section{LHBT tendinopathy}

It follows from the observation of a small group of patients ( $n=10)$ by McDevitt et al. that exercises of an eccentric-concentric character applied in patients with chronic LHBT tendinopathy may be useful in fighting pain, but this requires further observation [106].

\section{SIS}

In the case of shoulder pain caused by SIS, physical therapy is often the first choice for therapy. However, the therapeutic effectiveness of the applied methods is not always confirmed in literature. For this reason, people continue to look for new solutions [101].

The results obtained by Worsley et al. suggest that 1 week of exercises, including motor control training for the scapula, strengthening of the trapezius dorsi muscle and serratus anterior muscles, manual techniques recovering the flexibility of shortened muscles (e.g. stretch, trigger point therapy), may improve functionality and reduce pain in younger people with signs of subacromial conflict [100]. However, according to the authors, the research should be repeated on a larger population, with randomization.

Another randomized trial conducted by the Scandinavian team of Engebretsen et al. compared the effectiveness of supervised exercises to shockwave in patients experiencing pain in the subacromial area. After 18 weeks, $64 \%$ of patients (32 persons) in the exercising group experienced reduced shoulder pain and improvement of disability in comparison with 36\% (18 persons) in the subgroup treated with shockwaves. It was demonstrated that a significantly higher percentage rate of patients in the subgroup with supervised exercises experienced an improvement (odds ratio $3.2,95 \%$ confidence interval $=1.3$ to 7.8 ). In the exercising subgroup, significantly more patients returned to work $(p=0.016)$ [107]. Similar results were demonstrated by the above-mentioned research group in a publication from 2011. 29 (60\%) participants in the SE (supervised exercises) subgroup supervised by a physical therapist, in comparison with 24 (52\%) participants in the rESWT (radial extracorporeal shockwave therapy), demonstrated clinical improvement. Fewer patients in the SE subgroup required additional treatment in the period between 18 weeks and 1 year [107].

In the rehabilitation program proposed by other authors, in the first period, the objective of therapy was to relax the tense muscle, and then start manual and flexible resistance for the muscles cooperating with the scapula, thus improving joint movement. The therapy included the rehabilitation program used in the trials of other authors [101, 102].

In their research, Moezy et al. assumed that the potential cause of subacromial conflict may be dysfunction in the biokinematic chain caused by debilitation of the scapula stabilizers (levator scapulae muscle, rhomboid muscles, serratus anterior muscle, trapezius dorsi muscle). Lack of synergy among muscles, disrupted timing, a decrease in nerve-muscle coordination, debilitation, changed activity result in untypical loads, thus leading to subacromial compression [63]. In the proposed therapy, a team of researchers compared the impact of the applied therapy on improvement of movement range, the painkilling effect and scapula movement control in two subgroups. The first 
subgroup (ET - Exercises Therapy) underwent a 6-week cycle of supervised exercises, and the other subgroup (PT - Physical Therapy) underwent 6 weeks of physical procedures (Solux lamp, TENS, UD) together with exercises. The resultant analysis indicated that despite reduction in the level of pain on the VAS scale, no significant statistical differences were achieved. However, the ET subgroup demonstrated considerable different mobility of the shoulder joint. The authors believe that effect is a result of exercises reducing the tension of the shoulder joint capsule and the recovering flexibility of the pectoralis major muscle. Therefore, in SIS, inclusion of scapula rehabilitation exercises in the program seems to be justified [64]. The Swedish authors who presented the algorithm for physical therapy in treating shoulder pain agreed with these conclusions. An expert panel consisting of physical therapists agreed on the main principles of using motor therapy in shoulder pain (limited number of exercises, performed with proper scapular-humeral coordination, alignment of the humeral joint, gradual introduction of exercises without causing shoulder pain). The algorithm emphasizes that decisions regarding physiotherapy should be based on the results of clinical assessment and not on structural pathology. Furthermore, it was confirmed that the main physiotherapeutic intervention in treatment of shoulder pain and dysfunction is associated with active motor therapy. Available data suggests that a supervised program of exercises brings about clinical benefits in short- and long-term observation in comparison to no treatment or a placebo. Despite the growing evidence for the significance of physiotherapy (in particular motor therapy) in the treatment of shoulder pain, there is no consensus regarding the most effective exercise strategy [5]

The results demonstrated by the team of Aytar et al. indicate that a rehabilitation program with scapula mobilization did not significantly affect functional improvement, increased range of movement, reduced pain or satisfaction of patients with SIS syndrome [57].

The article by Gebremariam et al. was equally skeptical regarding the effectiveness of physiotherapeutic methods in subacromial impingement syndrome. Although the authors argue that some methods, despite moderate evidence of their effectiveness, seem promising in the treatment of SIS. At the same time, they emphasize that further research based on a higher class of evidence is required [65].

It follows from the research conducted by the team of Abdulla et al. that the effectiveness of supervised exercises, conducted independently or in combination with exercises performed in home conditions, is similar to invasive surgery in subacromial conflict syndrome [108]. It follows from a systematic review of literature prepared by other authors that there is little repeatable evidence to confirm the effectiveness of corticosteroid injections in treating rotator cuff subacromial conflict [109].

\section{Frozen shoulder}

Le et al. emphasize that treatment of frozen shoulder continues to be an unresolved clinical problem. So far, no universal conservative treatment algorithm has been developed; therefore, therapy should be adapted to the patient [31]. Adhesive capsulitis is often considered a self-limiting disease that subsides between the $1^{\text {st }}$ and $3^{\text {rd }}$ year of existence. However, various research has demonstrated that $20-50 \%$ of patients may develop chronic symptoms [31]. Three types of methods are possible in frozen shoulder treatment: conservative, pharmacological and surgical treatment in lack of progress from non-invasive treatment.

As for physiotherapy, there is no consensus as to the type, frequency or intensity of exercises. It follows from analyzing the research results published in the Cochrane Collaboration of Systematic Reviews that the effects of manual therapy and physical exercises are comparable to the therapeutic results of glucocorticosteroid injections and arthroscopic subacromial decompression, but these conclusions are based on evidence of poor quality [70].

The selection of the approach to treatment depends on the patient's functional status at the time of clinical examination. Principally, some researchers believe that conservative therapy should be continued for 6 months, with the level of pain monitored over this period [69].

Conservative treatment includes oral pharmacotherapy with nonsteroidal anti-inflammatory drugs (NSAID), intraarticular injections of hyaluronic acid and corticosteroids, as well as physical therapy.

However, Calis et al., in a comparative study, demonstrated that intraarticular injections of hyaluronic acid were less effective than intraarticular injections of corticosteroids or physical therapy in the treatment of frozen shoulder [110].

In turn, in an RCT, Hsieh et al. demonstrated that adding injections of hyaluronic acid to conventional physical therapy did not result in significant benefits in the treatment of patients with FS, and thus such injections may unnecessarily generate additional costs of treatment [111]. It also follows from analyzing the studies published in the Cochrane Library that the effects of annual therapy and exercises may be comparable to injections of glucocorticosteroids and invasive surgical intervention, but this conclusion is based on evidence of poor quality [112].

Although physical therapy is included in FS therapy, there are no unequivocal guidelines for the selection of therapeutic methods. Selection of the most effective option will be determined by the clinical condition for the patient and by observation of progress in pain elimination and functional improvement. In a study by Diercks et al., what was noted was the impact of exercise intensity on the outcome of therapy in patients with FS. The results of two subgroups of patients were compared: undergoing therapy of high and low intensity (including passive stretching and mobilization above the pain threshold vs. actively supported exercises within pain limits). After two years, only $63 \%$ of people from the first subgroup and $89 \%$ from the second subgroup achieved satisfactory functionality of the shoulder joint [113]. In literature, there is still no consensus as to which therapeutic option is better, mainly due to the absence of high-quality evidence. However, it should be emphasized that, regardless of the stage of disease, the most important objectives are eliminating pain, removing joint stiffness, maintaining correct movement range and recovering functionality [69].

\section{Orthopedic equipment and work ergonomics}

In chronic inflammatory conditions of the shoulder, in the cases of light damage to soft tissues of the shoulder joint and in the cases of mechanical overloading and degenerative lesions, flexible stabilization braces (bands) are often used. They cover the acromioclavicular joint, the shoulder joint and the shoulder. They are made of soft and/or flexible materials and are equipped with additional belts bringing the shoulder closer to the chest, and some cover the opposite part of the chest. These types of bands are effective in supporting the shoulder in muscle debilitation conditions and reduce joint loads with various types of pains, improve joint compactness after injuries of capsules and, additionally, stabilize the scapula. Band-type braces work well in early therapeutic interventions and perfectly supplement physical therapy. In inflammatory conditions of the soft tissues surrounding the shoulder, when it is not always necessary to limit mobility, more advanced structures are applied which, in the SICAMMP classification, are called stabilization rigid braces with possibility of movement. We should also take into consideration various other types of braces, such as slings, which are very useful in the therapy of patients with increased muscle tone while resting, in order to consolidate the therapeutic effects after a massage normalizing muscle tone $[82,83]$. 


\section{Summary}

The authors of the recommendations note that, apart from an injury-related dysfunction, each of the above-mentioned pains demonstrate a similar mechanism of development. Incorrect distribution of muscle tone in the shoulder area causes disturbance in innervation and blood supply, which manifests in a feeling of disruption, tingling, local feeling of cold, debilitation of muscle strength and, in the long run, structural lesions, thus translating to more or less abrupt lesion dynamics resulting in gradual loss of local mobility. According to the authors, the aims of recovering the correct spatial system, called structural homeostasis, in the shoulder girdle, is, first of all, normalization of muscle tension (regardless of the etiopathogenesis of the pain) and then inclusion in a rehabilitation program covering the methods of recovering and consolidating the correct models of motor activity.

As a result, the authors suggest starting with a massage for the purpose of recovering proper resting muscle and fascia tone as the foundation for further recovery of disrupted functionality of the shoulder complex. According to the authors, while looking for effective and cost-effective solutions for patients with painful shoulder syndrome, massage should be supplemented with the procedures in the scope of kinesiotherapy, physiotherapy and orthopedic equipment, while emphasizing the significance of patient education and autotherapy after instruction. The basis for deliberations in the search for the most effective model for treating patients with shoulder pain is the guidelines included in the article entitled: "Consensus for physiotherapy for shoulder pain". The authors of this publication emphasize the significance of clinical assessment in determination of the cases of functional deficit. Authors of the publication emphasize the importance of clinical evaluation in diagnostics causes of functional deficits. The more so that the analysis of imaging studies sometimes indicates the presence of structural changes in the shoulder in people without clinical symptoms, and sometimes shows a weak relationship between the level of shoulder pain and disability and the level of structural deficit detected during imaging. These observations challenge the validity of imaging procedures for the purposes of determining the source of symptoms in the shoulder and emphasize the significance of a detailed clinical assessment as the foundation for determining the aims of treatment [5]. It follows from a review of literature that researchers continue to search for the most effective solutions, supported with evidence, for treating painful shoulder syndrome.

The remarks included in the above-mentioned article, as well as the recommendations for treatment of pain in the spine, hip and now also shoulder in primary care, provide an opinion in the discussion associated with looking for the best practices in treatment of this type of dysfunction on the basis of cooperation between family physicians and physical therapists.

Source of funding: This work was funded by the author's own resources.

Conflict of interest: The authors declare no conflict of interests.

\section{References}

1. Artus $M$, Campbell $P$, Mallen $C D$, et al. Generic prognostic factors for musculoskeletal pain in primary care: a systematic review. $B M J$ Open 2017; 7: e012901, doi: 10.1136/bmjopen-2016-012901.

2. Greenberg DL. Evaluation and treatment of shoulder pain. Med Clin N Am 2014; 98(3): 487-504.

3. Hutting N, Heerkens $\mathrm{YF}$, Engels JA, et al. Experiences of employees with arm, neck or shoulder complaints: a focus group study. $B M C$ Musculoskelet Disord 2014; 15: 141, doi: 10.1186/1471-2474-15-141.

4. Karel YHJM, Scholten-Peeters GGM, Thoomes-de Graaf M, et al. Physiotherapy for patients with shoulder pain in primary care: a descriptive study of diagnostic - and therapeutic management. Physiotherapy 2017; 103(4): 369-378.

5. Johansson K, Maenhout AG, Jane S, et al. Consensus for physiotherapy for shoulder pain. International Orthopaedics 2015; 39(4): 715-720.

6. Marik T, Roll S. Effectiveness of occupational therapy interventions for musculoskeletal shoulder conditions: a systematic review. Am J Occup Ther 2017; 71(1): 1-11.

7. Whittle S, Buchbinder R. In the clinic. Rotator cuff disease. Ann Intern Med 2015; 162(1): ITC1-15, doi: 10.7326/AITC201501060.

8. Diercks R, Bron C, Correstijn $\mathrm{O}$, et al. Guideline for diagnosis and treatment of subacromial pain syndrome: a multidisciplinary review by the Dutch Orthopaedic Association. Acta Orthop 2014; 85(3): 314-322.

9. Verhagen AP, Bierma-Zeinstra SMA, Burdorf A, et al. Conservative interventions for treating work-related complaints of the arm, neck or shoulder in adults. Cochrane Database Syst Rev 2013; 12(12): CD008742, doi: 10.1002/14651858.CD008742.pub2.

10. Tashjian RZ. Epidemiology, natural history, and indications for treatment of rotator cuff tears. Clin Sports Med 2012; 31(4): 589-604.

11. Laslett M, Steele M, Hing W, et al. Shoulder pain patients in primary care - Part 1: Clinical outcomes over 12 months following standardized diagnostic workup, corticosteroid injections, and community-based care. J Rehabil Med 2014; 46: 898-907.

12. Chester R, Shepstone L, Daniell H, et al. Predicting response to physiotherapy treatment for musculoskeletal shoulder pain: a systematic review. BMC Musculoskeletal Disord 2013; 14: 203-220.

13. Robb G, Arroll B, Reid D, et al. Summary of an evidence-based guideline on soft tissue shoulder injuries and related disorders - Part 2: Management. J Prim Health Care 2009; 1: 42-49.

14. Madadizadeh F, Vali L, Rafiei S, et al. Risk factors associated with musculoskeletal disorders of the neck and shoulder in the personnel of Kerman University of Medical Sciences Electron Physician. Electron Physician 2017; 9(5): 4341-4348.

15. Holtermann A, Hansen JV, Burr H, et al. Prognostic factors for long-term sickness absence among employees with neck-shoulder and low-back pain. Scand J Work Environ Health 2010; 36(1): 34-41.

16. Jain NB, Wilcox R, Katz JN, et al. Clinical examination of the rotator cuff. PMR 2013; 5(1): 45-56.

17. Kooijman MK, Barten DJA, Swinkels ICS, et al. Pain intensity, neck pain and longer duration of complaints predict poorer outcome in patients with shoulder pain - a systematic review. BMC Musculoskelet Disord 2015; 16: 288, doi: 10.1186/s12891-015-0738-4.

18. Petri M, Ettinger M, Brand S, et al. Non-operative management of rotator cuff tears. The Open Orthop J 2016; 10(Suppl 1: M11): 349-356.

19. Reilly P, Macleod I, Macfarlane R, et al. Dead men and radiologists don't lie: a review of cadaveric and radiological studies of rotator cuff tear prevalence. Ann R Coll Surg Engl 2006; 88(2): 116-121.

20. Vitale MA, Vitale MG, Zivin JG, et al. Rotator cuff repair: an analysis of utility scores and cost-effectiveness. J Shoulder Elbow Surg 2007; 16(2): 181-187.

21. Mathiasen R, Hogrefe C. Evaluation and management of rotator cuff tears: a primary care perspective. Curr Rev Musculoskelet Med 2018; 11(1): 72-76. 
22. Kassolik K, Rajkowska-Labon E, Tomasik T, et al. Recommendations of the Polish Society of Physiotherapy, the Polish Society of Family Medicine and the College of Family Physicians in Poland in the field of physiotherapy of back pain syndromes in primary health care. Fam Med Prim Care Rev 2017; 19(3): 323-334.

23. Tangrood ZJ, Gisselman AS, Sole G, et al. Clinical course of pain and disability in patients with subacromial shoulder pain: a systematic review protocol. BMJ Open 2018; 8(5): e019393, doi: 10.1136/bmjopen-2017-019393.

24. Kulkarni K, Gibson J, Brownson P, et al. Subacromial shoulder pain. Shoulder Elbow 2015; 7(2): 135-143.

25. Zappia Z, Di Pietto F, Aliprandi A, et al. Multi-modal imaging of adhesive capsulitis of the shoulder. Insights Imaging 2016; 7(3): 365-371.

26. Linaker CH, Walker-Bone K. Shoulder disorders and occupation. Best Pract Res Clin Rheumatol 2015; 29(3): 405-423.

27. Läderman A, Denard PJ, Collin P. Massive rotator cuff tears: definition and treatment. Int Orthop 2015; 39(12): $2403-2412$.

28. Dziak A, Tayara SH, ed. Bolesny bark. Kraków: Kasper s.c. 1998: 38-78 (in Polish).

29. Singaraju VM, Kang RW, Yanke AB, et al. Biceps tendinitis in chronic rotator cuff tears: a histologic perspective. J Shoulder Elbow Surg 2008; 17(6): 898-904.

30. Hsu JE, Anakwenze OA, Warrender WJ, et al. Current review of adhesive capsulitis. J Shoulder Elbow Surg 2011; 20(3): 502-514.

31. Le HV, Lee SJ, Nazarian A, et al. Adhesive capsulitis of the shoulder: review of pathophysiology and current clinical treatments. Shoulder Elbow 2017; 9(2): 75-84.

32. Pribicevio M. The epidemiology of shoulder pain: a narrative review of the literature. In: Ghosh S, ed. Pain in perspective. 2012: 147-185, doi: 10.5772/2627.

33. Virta L, Joranger P, Brox JI, et al. Costs of shoulder pain and resource use in primary health care: a cost-of-illness study in Sweden. BMC Musculoskelet Disord 2012; 13: 1, doi: 10.1186/1471-2474-13-17.

34. Huisstede BMA, Wijnhoven HA, Bierma-Zeinstra SM, et al. Prevalence and characteristics of complaints of the arm, neck, and/or shoulder (CANS) in the open population. Clin J Pain 2008; 24: 253-259.

35. da Costa BR, Vieira ER. Risk factors for work-related musculoskeletal disorders: a systematic review of recent longitudinal studies. Am $J$ Ind Med 2010; 53(3): 285-323.

36. Pedersen MT, Andersen CH, Zebis M, et al. Implementation of specific strength training among industrial laboratory technicians: longterm effects on back, neck and upper extremity pain. BMC Musculoskelet Disord 2013; 14: 287-298.

37. Kaliniene G, Ustinaviciene R, Skemiene L, et al. Associations between musculoskeletal pain and work-related factors among public service sector computer workers in Kaunas County, Lithuania. BMC Musculoskelet Disord 2016; 17: 420, doi: 10.1186/s12891-016-1281-7.

38. Bau JG, Chia T, Wei SH, et al Correlations of neck/shoulder perfusion characteristics and pain symptoms of the female office workers with sedentary lifestyle. PLoS One 2017; 12(1): e0169318, doi: 10.1371/journal.pone.0169318.

39. Yasobant S, Rajkumar P. Work-related musculoskeletal disorders among health care professionals: a cross-sectional assessment of risk factors in a tertiary hospital, India. Indian J Occup Environ Med 2014; 18(2): 75-81.

40. Long $\mathrm{MH}$, Bogossian FE, Johnston V. The prevalence of work-related neck, shoulder, and upper back musculoskeletal disorders among midwives, nurses, and physicians: a systematic review. Workplace Health Saf 2013; 61(5): 223-229.

41. Prudhvi K, Murthy KR. Self-reported musculoskeletal pain among dentists in Visakhapatnam: a 12-month prevalencestudy. Indian J Dent Res 2016; 27(4): 348-352.

42. Yan $\mathrm{P}$, Yang $\mathrm{Y}$, Zhang $\mathrm{L}$, et al. Correlation analysis between work-related musculoskeletal disorders and the nursing practice environment, quality of life, and social support in the nursing professionals. Medicine (Baltimore) 2018; 97(9): e0026, doi: 10.1097/ MD.0000000000010026.

43. Zhang D, Huang H. Prevalence of work-related musculoskeletal disorders among sonographers in China: results from a national webbased survey. J Occup Health 2017; 59(6): 529-541.

44. Oude Hengel KM, Visser B, Sluiter JK. The prevalence and incidence of musculoskeletal symptoms among hospital physicians: a systematic review. Int Arch Occup Environ Health 2011; 84(2): 115-119.

45. Epstein S, Sparer EH, Tran BN, et al. Prevalence of work-related musculoskeletal disorders among surgeons and interventionalists: a systematic review and meta-analysis. JAMA Surg 2018; 153(2): e174947, doi: 10.1001/jamasurg.2017.4947.

46. Huang SW, Lin JW, Wang WT, et al. Hyperthyroidism is a risk factor for developing adhesive capsulitis of the shoulder: a nationwide longitudinal population-based study. Sci Rep 2014; 4: 4183, doi: 010.1038/srep04183.

47. Oliveira VMA, Pitangui ACR, Gomes MRA, et al. Shoulder pain in adolescent athletes: prevalence, associated factors and its influence on upper limb function. Braz J Phys Ther 2017; 21(2): 107-113.

48. Frisch KE, Clark J, Hanson C, et al. High prevalence of nontraumatic shoulder pain in a regional sample of female high school volleyball athletes. Orthop J Sports Med 2017; 5(6): 2325967117712236, doi: 10.1177/2325967117712236.

49. Abrams GD, Renstrom PA, Safran MR. Epidemiology of musculoskeletal injury in the tennis player. Br J Sports Med 2012; 46(7): 492-498 , doi: 10.1136/bjsports-2012-091164.

50. Heyward OW, Vegter RJK, de Groot S. Shoulder complaints in wheelchair athletes: a systematic review. PLoS One 2017; 12(11): e0188410, doi: 10.1371/journal.pone.0188410.

51. Shanahan EM, Sladek R. Shoulder pain at the workplace. Best Pract Res Clin Rheumatol 2011; 25(1): 59-68.

52. Boocock MG, Collier JMK, McNair PJ, et al. A framework for the classification and diagnosis of work-related upper extremity conditions; systematic review. Semin Arth Rheum 2009; 38: 289-231.

53. Martinez-Calderon J, Meeus M, Struyf F, et al. The role of psychological factors in the perpetuation of pain intensity and disability in people with chronic shoulder pain: a systematic review. BMJ Open 2018; 8(4): e020703, doi: 10.1136/bmjopen-2017-020703.

54. Montano D. Upper body and lower limbs musculoskeletal symptoms and health inequalities in Europe: an analysis of cross-sectional data. BMC Musculoskelet Disord 2014; 15: 285, doi: 10.1186/1471-2474-15-285.

55. Pope DP, Silman AJ, Cherry NM, et al. Association of occupational physical demands and psychosocial working environment with disabling shoulder pain. Ann Rheum Dis 2001; 60(9): 852-858.

56. Li J, Chen J, Qin Q, et al. Chronic pain and its association with obesity among older adults in China. Arch Gerontol Geriatr 2018; 76 : $12-18$.

57. Aytar A, Baltaci G, Uhl T, et al. The effects of scapular mobilization in patients with subacromial impingement syndrome: a randomized, double-blind, placebo-controlled clinical trial. J Sport Rehabil 2015; 24(2): 116-129.

58. Yamaguchi K, Ditsios K, Middleton WD, et al. The demographic and morphological features of rotator cuff disease. A comparison of asymptomatic and symptomatic shoulders. J Bone Joint Surg Am 2006; 88(8): 1699-1704.

59. Raney EB, Thankam FG, Dilisio MF, et al. Pain and the pathogenesis of biceps tendinopathy. Am J Transl Res 2017; 9(6): $2668-2683$.

60. Redondo-Alonso L, Chamorro-Moriana G, Jimenez-Rejano JJ, et al. Relationship between chronic pathologies of the supraspinatus tendon and the long head of the biceps tendon: systematic review. BMC Musculoskelet Disord 2014; 15: 377-387.

61. Murthi AM, Vosburgh CL, Neviaser TJ. The incidence of pathologic changes of the long head of the biceps tendon. J Shoulder Elbow Surg 2000; 9(5): 382-385. 
62. Braun S, Horan MP, Elser F, et al. Lesions of the biceps pulley. Am J Sports Med 2011; 39(4): 790-795.

63. Moezy A, Sepehrifar S, Dodaran M. The effects of scapular stabilization based exercise therapy on pain, posture, flexibility and shoulder mobility in patients with shoulder impingement syndrome: a controlled randomized clinical trial. Med J Islam Repub Iran 2014; 28(87): $1-15$.

64. Tangtrakulwanich B, Kapkird A. Analyses of possible risk factors for subacromial impingement syndrome. World J Orthop 2012; 3(1): 5-9.

65. Gebremariam L, Hay EM, Sande RV, et al. Subacromial impingement syndrome - effectiveness of physiotherapy and manual therapy. Br J Sports Med 2013; 48(16): 1202-1208.

66. Kessel L. Bóle barku spowodowane patologiq ortopedycznq. In: Dziak A, Tayara SH, ed. Bolesny bark. Kraków: Kasper s.c. 1998: 123-173 (in Polish).

67. Tonino PM, Gerber Ch, Itoi E, et al. Complex shoulder disorders: evaluation and treatment. J Am Acad Orthop Surg 2009; 17(3): 125-136.

68. Prodromidis AD, Charalambous CP. Is there a genetic predisposition to frozen shoulder? A systematic review and meta-analysis. JBJS Rev 2016; 4(2), doi: 10.2106/JBJS.RVW.0.00007.

69. Georgiannos D, Markopoulos G, Devetzi E, et al. Adhesive capsulitis of the shoulder. Is there consensus regarding the treatment? A comprehensive review. Open Orthop J 2017; 11(Suppl. 1, M2): 65-76.

70. Page MJ, Green S, Mrocki MA, et al. Electrotherapy modalities for rotator cuff disease. Cochrane Database Syst Rev 2016; (6): CD012225, doi: 10.1002/14651858.CD012225.

71. Angst F, Schwyzer HK, Aeschlimann A, et al. Measures of adult shoulder function: isabilities of the Arm, Shoulder, and Hand Questionnaire (DASH) and its short version (QuickDASH), Shoulder Pain and Disability Index (SPADI), American Shoulder and Elbow Surgeons (ASES) Society standardized shoulder assessment form, Constant (Murley) Score (CS), Simple Shoulder Test (SST), Oxford Shoulder Score (OSS), Shoulder Disability Questionnaire (SDQ), and Western Ontario Shoulder Instability Index (WOSI). Arthritis Care Res (Hoboken) 2011; 63(Suppl. 11): S174-S188.

72. van Kampen DA, van den Berg T, van der Woude $\mathrm{HJ}$, et al. The diagnostic value of the combination of patient characteristics, history, and clinical shoulder tests for the diagnosis of rotator cuff tear. J Orthop Surg Res 2014; 9: 70, doi: 10.1186/s13018-014-0070-y.

73. Longo UG, Berton A, Marinozzi A, et al. Subscapularis tears. Med Sport Sci 2012; 57: 114-121.

74. Robinson CM, Seah KT, Chee YH, et al. Frozen shoulder. J Bone Joint Surg Br 2012: 94(1): 1-9, doi: 10.1302/0301-620X.94B1.27093.

75. Sergienko S, Kalichman L. Myofascial origin of shoulder pain: a literature review. J Bodyw Mov Ther 2015; 19(1): 91-101.

76. Andrzejewski W, Kassolik K, Cymer K. Poziom korelacji między wrażliwością uciskową mierzoną na przyczepie kostnym i na przebiegu mięśni szkieletowych. Fam Med Prim Care Rev 2009; 11(2): 127-133 (in Polish).

77. Andrzejewski W, Kassolik K. Ocena palpacyjna w masażu tensegracyjnym. Fizjoterapia 2009; 17(4): 60-66 (in Polish).

78. Travell JG, Simons DG. Myofascial pain and dysfunction the trigger point manual. Baltimore: Williams \& Wilkins; 1984.

79. Kassolik K, Andrzejewski W. Masaż tensegracyjny. Fizjoterapia 2010; 18(1): $66-71$ (in Polish).

80. Kassolik K, Andrzejewski W. Masaż tensegracyjny. Wrocław: MedPharm Polska; 2014 (in Polish).

81. Kassolik K, Andrzejewski W, Brzozowski M, et al. Comparison of massage based on the tensegrity principle and classic massage in treating chronic shoulder pain. J Manipulative Physiol Ther 2013; 36(7): 418-427.

82. Gieremek K, Janicki S, Przeździak B, et al. Wyroby medyczne. Zaopatrzenie indywidualne. Warszawa: Wydawnictwo Lekarskie PZWL; 2016 (in Polish).

83. Przeździak B, Nyka W. Zastosowanie kliniczne protez, ortez i środków pomocniczych. Gdańsk: Via Medica; 2008 (in Polish).

84. Fryer G. Muscle energy technique: an evidence-informed approach. Int J Osteopathic Med 2011; 14(1): 3-9.

85. Kong LJ, Zhan HS, Cheng YW, et al. Massage therapy for neck and shoulder pain: a systematic review and meta-analysis. Evid Based Complement Alternat Med 2013: 613279, doi: 10.1155/2013/613279.

86. Kassolik K, Andrzejewski W, Trzęsicka E. Role of the tensegrity rule in theoretical basis of massage therapy. J Back Musculoskelet 2013; 20(1): 15-20.

87. White PF, Lazo OLE, Galeas L, et al. Use of electroanalgesia and laser therapies as alternatives to opioids for acute and chronic pain management. F1000Res 2017; 6: 2161, doi: 10.12688/f1000research.12324.1.

88. Pekyavas NO, Baltaci G. Short-term effects of high-intensity laser therapy, manual therapy, and Kinesio taping in patients with subacromial impingement syndrome. Lasers Med Sci 2016; 31(6): 1133-1141.

89. Dundar U, Turkmen U, Toktas $\mathrm{H}$, et al. Effect of high-intensity laser therapy in the management of myofascial pain syndrome of the trapezius: a double-blind, placebo-controlled study. Lasers Med Sci 2015; 30(1): 325-332.

90. Yu H, Côté P, Shearer HM, et al. Effectiveness of passive physical modalities for shoulder pain: systematic review by the Ontario protocol for traffic injury management collaboration. Phys Ther 2015; 95(3): 306-318.

91. Page MJ, Green S, Kramer S, et al. Electrotherapy modalities for adhesive capsulitis (frozen shoulder). Cochrane Database Syst Rev 2014; 10: CD011324, doi: 10.1002/14651858.CD011324.

92. Rayegani S, Bahrami M, Samadi B, et al. Comparison of the effects of low energy laser and ultrasound in treatment of shoulder myofascial pain syndrome: a randomized single-blinded clinical trial. Eur J Phys Rehabil Med 2011; 47(3): 381-389.

93. Robertson VJ, Baker KG. A review of therapeutic ultrasound: effectiveness studies. Phys Ther 2001; 81(7): 1339-1350.

94. Gomes CAFP, Dibai-Filho AV, Moreira WA, et al. Effect of adding interferential current in an exercise and manual therapy program for patients with unilateral shoulder impingement syndrome: a randomized clinical trial. J Manipulative Physiol Ther 2018; 41(3): $218-226$.

95. Rabini A, Piazzini DB, Bertolini C, et al. Effects of local microwave diathermy on shoulder pain and function in patients with rotator cuff tendinopathy in comparison to subacromial corticosteroid injections: a single-blind randomized trial. J Orthop Sports Phys Ther 2012; 42(4): 363-370.

96. Preis R. Ramię i bark. In: Preis R, Elbert-Paprotny G, ed. Fizjoterapia. Wrocław: Elsevier Urban \& Partner; 2012 (in Polish).

97. Kuhn JE. Exercise in the treatment of rotator cuff impingement: a systematic review and a synthesized evidence-based rehabilitation protocol. J Shoulder Elbow Surg 2009; 18: 138-160.

98. Engebretsen K, Grotle M, Bautz-Holter E, et al. Supervised exercises compared with radial extracorporeal shock-wave therapy for subacromialshoulder pain: 1-year results of a single-blind randomized controlled trial. Phys Ther 2011; 91(1): 37-47.

99. Zebis MK, Andersen LL, Pedersen MT, et al. Implementation of neck/shoulder exercises for pain relief among industrial workers: a randomized controlled trial. BMC Musculoskeletal Disord 2011; 21(12): 205-214.

100. Worsley P, Warner M, Mottram S, et al. Motor control retraining exercises for shoulder impingement: effects on function, muscle activation and biomechanics in young adults. J Shoulder Elbow Surg 2013; 22(4): e11-e19, doi: 10.1016/j.jse.2012.06.010.

101. Bohmer A, Staff PH, Brox JI. Supervised exercises in relation to rotator cuff disease (impingement syndrome, stages 1 and II): a treatment regimen and its regionale. Physiother Theory Pract 1998; 14: 93-105. 
102. Virta L, Mortensen M, Eriksson R, et al. How many patients with subacromial impingement syndrome recover with physiotherapy: a follow-up study of a supervised exercise programme. Adv Physiother 2009; 11: 166-173.

103. Ludewig PM, Borstad JD. Effects of a home exercise programme on shoulder pain and functional status in construction workers. Occup Environ Med 2003; 60: 841-849.

104. Walther M, Werner A, Stahlschmidt T, et al. The subacromial impingement syndrome of the shoulder treated by conventional physiotherapy, self-training, and a shoulder brace: results of a prospective, randomized study. J Shoulder Elbow Surg 2004; 13: 417-423.

105. van der Heijden GJ. Shoulder disorders: a state-of-the-art review. Baillieres Best Pract Res Clin Rheumatol 1999; 13(2): $287-309$.

106. McDevitt AW, Snodgrass SJ, Cleland JA, et al. Treatment of individuals with chronic bicipital tendinopathy using dry needling, eccentricconcentric exercise and stretching; a case series. Physiother Theory Pract 2018; 22: 1-11, doi: 10.1080/09593985.2018.1488023

107. Engebretsen K, Grotle M, Bautz-Holter E, et al. Radial extracorporeal shockwave treatment compared with supervised exercises in patients with subacromial pain syndrome: single blind randomised study. BMJ 2009; 339: b3360, doi: 10.1136/bmj.b3360.

108. Abdulla SY, Southerst D, Côté $P$, et al. Is exercise effective for the management of subacromial impingement syndrome and other soft tissue injuries of the shoulder? A systematic review by the Ontario Protocol for Traffic Injury Management (OPTIMa) Collaboration. Man Ther 2015; 20(5): 646-656.

109. Koester MC, Dunn WR, Kuhn JE, et al. The efficacy of subacromial corticosteroid injection in the treatment of rotator cuff disease: a systematic review. J Am Acad Orthop Surg 2007; 15(1): 3-11.

110. Calis M, Demir H, Ulker S, et al. Is intraarticular sodium hyaluronate injection an alternative treatment in patients with adhesive capsulitis? Rheumatol Int 2006; 26(6): 536-540.

111. Hsieh LF, Hsu WC, Lin YJ, et al. Addition of intra-articular hyaluronate injection to physical therapy program produces no extra benefits in patients with adhesive capsulitis of the shoulder: a randomized controlled trial. Arch Phys Med Rehabil 2012; 93(6): 957-964.

112. Page MJ, Green S, McBain B, et al. Manual therapy and exercise for rotator cuff disease (Review). Cochrane Database Syst Rev 2016; 6: CD012224, doi: 10.1002/14651858.CD012224.

113. Diercks RL, Stevens M. Gentle thawing of the frozen shoulder: a prospective study of supervised neglect versus intensive physical therapy in seventy-seven patients with frozen shoulder syndrome followed up for two years. J Shoulder Elbow Surg 2004; 13(5): 499-502.

Tables: 2

Figures: 0

References: 113

Received: 26.04 .2018

Reviewed: 03.05.2018

Accepted: 04.05.2018

Address for correspondence:

Krzysztof Kassolik, MD, PhD, Assoc. Prof.

Wydział Fizjoterapii AWF

Al. I.J. Paderewskiego 35

51-612 Wrocław

Polska

Tel.: +48 71 347-30-89

E-mail: krzysztof.kassolik@awf.wroc.pl;

krzysztof.kassolik@gmail.com 